\title{
Let me tell you a story ... intellectual property, character, narration*
}

\author{
Johanna Gibson \\ Herchel Smith Professor of Intellectual Property Law and Director, Queen Mary Intellectual Property \\ Research Institute (QMIPRI), Centre for Commercial Law Studies (CCLS), Queen Mary University of \\ London and Director, The Intellectual Property Institute (registered charity 283150)
}

Intellectual property is that area of law most closely preoccupied with a society's cultural output and creative self, in that it is that system which identifies the 'author', protects the cultural materials produced by the creator, and allows for commercialisation of those materials within the increasingly significant knowledge economy. In this way, the intellectual property system narrates society and suggests its cultural progress, legitimating certain materials emanating from that society - sufficiently original, sufficiently inventive, sufficiently distinctive, sufficiently new. What is the role of intellectual property in authenticating our society and what existence is there for materials produced and understood outside the framework of patents, copyright, trade marks and designs and the like? Is there a world outside the world view of copyright? This paper will illustrate the performance of intellectual property through a series of events and identities, and the building of creative communities through narration.

Keywords: intellectual property, narrative and narration, traditional knowledge, culture, cultural heritage, cultural diversity, cultural expression, Otterhound

Inaugurate comes from the Latin, meaning to take omens from the flight of birds that is, meaning and judgement taken from an action, a gesture, as distinct from language. The Roman Empire was known for its reliance on birds as signs from the gods before taking political decisions. Flight is itself a becoming or a journey, at the very least a change of place and perspective. And an inaugural is a beginning of a new office (delays in scheduling aside!), an introduction, a commencement, it is the new. An inaugural is both a destination marking the passage to this point, and the beginning. And what I am faced with today is an incredible journey. A journey that has taken me across continents, across disciplines and along which I have met and worked with incredible people. I have in this audience, leaders of the legal community, including some of the most respected experts in intellectual property in the world, and at the same time, those coming to intellectual property for the first time.

I thought I had found an inaugural lecture. Yet these augural observations, as usual, come camouflaged. ${ }^{1}$

* Inaugural lecture, Derek Willoughby Lecture Theatre, Queen Mary University of London, Charterhouse Square, London, 11 May 2011.

1. Serres M, The Five Senses: A Philosophy of Mingled Bodies (I), M Sankey \& P Cowley (trans), London, Continuum, 2008 [1985], page 103. 
I thought I found an inaugural, but perhaps what I am saying comes inevitably camouflaged by the epic journey to this point. And indeed, if intellectual property is a tale then it is an epic.

An inaugural is by its very nature a personal narrative event, a personal epic. It is perhaps more personal than any other lecture I am likely to give. It is both the expression of my position and gratitude to my family and an acknowledgement of my friends and my intellectual community, as well as the rite of passage for what is a personal intellectual history. For that reason, it is especially fitting that I am delivering my inaugural in the open stage of the Derek Willoughby Lecture Theatre, as this was the venue for my very first lecture for Queen Mary, a lecture on Japanese Patent Law. And that this is a story, a story on speech, returns me to the beginning when I composed 'An Ethical Speech for Dumb Animals' (animal rights and speech) for my undergraduate honours paper. And my preoccupation with words has stuck with me. Like the epic poem, the end rhymes with the beginning, for an inaugural is, indeed, a beginning and also a resolution.

Even the story I am in the process of narrating reveals that any narrative whatsoever begins in the middle of things and that its so-called 'end' is an arbitrary cut in the infinite sequence of data ${ }^{2}$

It is the formal commencement of the professorial career, the ceremony by which the professor is installed into office. The dilemma perhaps is that the inaugural thereby marks both the end of something and the beginning. Just like telling a story, the question here is where in that story this tale begins. Similarly, in the narrative of innovation and creativity, how does one designate the beginning, middle and end? It may be that the story of intellectual property is a simple tale of idea, manifesting that idea and bringing it to life (in a book, in an invention), and sharing that life (through commercialisation and dissemination). Intriguingly, though, it is unclear whether commercialisation, like the inaugural, is in fact the end, the goal, or indeed the beginning of something else. That is, arguably commercialisation, in the intellectual property narrative, is just the start, the provocation for the followers (as distinct from imitators), the new innovators and creators, the continually progressive development of our societies and cultures. The judicial narrative operates in this way, in which precedent preserves and contributes to the narrative not as imitation but as a meaning immanent within the law.

The treasures of the narrative of intellectual property are those significant moments in the story, the turning-points, those inventive, distinctive, original, new and memorable, exemplary moments in intellectual history. Above all, intellectual property charts the new by defining the past.

The Library is unlimited and cyclical. If an eternal traveller were to cross it in any direction, after centuries he would see that the same volumes were repeated in the same disorder (which, thus repeated, would be an order: the Order). My solitude is gladdened by this elegant hope. ${ }^{3}$

What we have here then, in the epic narrative of intellectual property, is a tale of destiny. Just as an inaugural brings together the 'years of formation', ${ }^{4}$ so too does intellectual property suggest an 'autobiographical' epic of the product. What are the

2. Lyotard J-F, Peregrinations: Law, Form, Event, Columbia UP, 1988, page 2.

3. Borges JL, 'The Library of Babel', Labyrinths: Selected Stories and Other Writings, JE Irby (trans), DA Yates \& JE Irby (eds), New York, New Directions Books, 1964, page 58.

4. Lyotard J-F, Peregrinations: Law, Form, Event, Columbia UP, 1988, page 3. 
influences, the turning-points in the object's life that bring it to this point? For patent law, for instance, the wealth of prior art illustrates the interconnections of narratives within intellectual property. It is entirely integral to the object that the law understands exactly how it is situated with respect to the rest of the literature in the field. Where that story is resolved, in each case, is in the individual patent, the original piece of copyright, the new and characterful design, the distinctive trade mark. That resolution, however, might be challenged any time in that there is always a certain arbitrariness to that moment of resolution. 5

And my own narrative might appear to be similarly arbitrary: the threads of literature, cultural studies, sciences and commercial life, almost suddenly resolved in this particular moment of inauguration as a Professor of Law.

'Character' says Novalis, in one of his questionable aphorisms - 'character is destiny.' 6

Perhaps indeed that is why the inaugural can feel so much like a crisis point in this tale of destiny. I recall watching colleagues preparing for their own inaugurals in the past, gripped by the absolute fear of the vast scope of the task ahead. An impossible remit of showing one's family, this is what I do, and demonstrating to one's peers, that at the very least I do it interestingly. I found myself repeating the refrain - it's only an inaugural - in the same way that a few years previously I had repeated to myself - it's only a PhD. The very special character of the inaugural, however, is that it's not written for itself, it's composed for you.

Their copious stories, oftentimes begun,

End without audience, and are never done. ${ }^{7}$

It is about showing acknowledgement and respect to that community that helped me reach this goal today - the rich intellectual landscape in which I find myself exploring and the diversity of that community that is here today - judges, practitioners, industry, academics, friends and family. An inaugural is therefore a necessary demonstration to all of you that I am the genuine article - a genuine creator if you will. Indeed, it is this authenticity of the source of the intellectual product that underpins much of intellectual property law today.

So this is the intensely personal nature of the inaugural - it is the story by which I make the things I do intelligible. An inaugural similarly creates the self of the professor, and reaffirms the wider intellectual community of Queen Mary. 'Professor' is both like a certification mark and a brand.

And as teachers, we are also storytellers for new members of the community, bringing our students into this world and giving them the tools, insight, and enthusiasm to explore the plot-lines for themselves. We are mapping for our students the enormous terrain in such a way that they have the resources to make their own progress through the field themselves. And I am delighted to see so many of my students here today.

And this mapping is both intellectual and indeed geographical for me. My journey here has also been a kind of travel story for me, from commercial practice in Australia to academic life in the UK. So thrilling did I find the academic pursuit of intellectual property, that it motivated a complete shift from my original intentions and location. Perhaps indeed this was the turning point, the inauguration of intellectual property into my academic and intellectual life.

5. Lyotard J-F, Peregrinations: Law, Form, Event, Columbia UP, 1988, page 2.

6. Eliot G, The Mill on the Floss, 1860.

7. William Shakespeare, Venus and Adonis, Stanza 141. 
But then, intellectual property has, if you like, also inaugurated itself very successfully into the popular psyche and into our histories. It is so central that it appears in one of history's most significant peace treaties: the Treaty of Versailles, a treaty to end one of the bloodiest wars in history.

A little more personal, perhaps, my mother's love of Charles Dickens (and visiting Doughty Street every time she visits London) also has an interesting link to intellectual property in that Charles Dickens was a fierce advocate of international copyright protection for all authors. Unable to enjoy conventional copyright protection in the US, he was paid as a courtesy by his authorised publishers. However, unauthorised copies were subsequently produced and sold very cheaply, without paying any royalties to Dickens. Ironically, this mass circulation contributed to his celebrity in the US so that when he visited in 1867, delivering public readings of his works, he enjoyed additional and significant financial return through those appearances.

His endorsement of the official publisher also assisted in capturing the public, when he announced that Ticknor and Fields were "the sole authorized representatives in America, of the whole series of my books' (despite having received payments already by other publishers) ${ }^{8}$

Messrs Ticknor \& Fields, whose editions bear the author's imprimatur, and carry with them all the sanction that he can give in the absence of copyright, publish, we observe, in a neat pamphlet form, the selections read at each evening's entertainment by Mr Dickens, so that the hearers may have the original at their hand. (Publishers' Circular, 16 January 1868)

Nevertheless, notwithstanding the confusion and subsequent furore, the public was motivated by their love of the author to purchase the official versions rather than the multitude of cheaper copies, albeit legitimate ones. Dickens told a convincing story within which he invited his audience to participate as the authenticators of his 'official' version: a kind of 'self-help' copyright protection if you like through the anchor of Dickens, the genuine article, an early version of fan-based income and protection.

So perhaps part of the reason for the 'phenomenon' of intellectual property is the intensely personal nature of the subject matter itself that is at stake. It appears to be involved in every part of our day-to-day lives, from the trade mark on our breakfast cereal, to the copyright in the newspaper, to design protection for the kitchen chairs, to the patents protecting the latest engineering in your BlackBerry, it appears to govern the information embodied in all aspects of our daily lives. The story of intellectual property is my story, your story, we are all the protagonists in this tale. There is a recognisable community created by the story of intellectual property. The intellectual property system 'invents', it 'creates' the knowledge objects that indicate our cultural evolution.

And in our day-to-day lives, the intellectual property framework also purports to organise the entirety of our cultural output in such a way that it provides a thorough record, an account of events, a story - those arrested moments in the otherwise incremental evolution of our cultural and social innovation and creativity - those events are thus ordered as works (a book), inventions, tangible objects in an otherwise intangible library of human knowledge. This is the nature of cultural maturity, ${ }^{9}$ that we move beyond the uncertainty of relationships to the certainty of things, of objects - a

8. Seville C, The Internationalisation of Copyright Law: Books, Buccaneers and the Black Flag in the Nineteenth Century, Cambridge, Cambridge UP, 2009, page 194.

9. Serres M, The Five Senses: A Philosophy of Mingled Bodies (I), M Sankey \& P Cowley (trans), London, Continuum, 2008 [1985], page 39. 
displacement from emotional life to the objective examination of objects, ${ }^{10}$ a move from mere nostalgia of myth to the presence of wisdom. In this way also there is a relationship set up between the things themselves - how does one infringe upon another's copyright, patent rights, how does one copy, adapt, not copy, transform?

All of these conditions and possibilities are realised precisely because of the organised narrative of intellectual property. The intellectual property narrative transposes a framework by which to identify and understand what is original, what is distinctive, what is a copy, what is authentic. Indeed, these concepts come to life because of the intellectual property framework - in many ways they do not make sense without it. It creates meaning in our cultural output and secures identity attaching to those products. Intellectual property takes an otherwise undifferentiated field of intellectual activity and creates a temporal, historical sequence of events. It monitors and gauges those events with respect to known and accepted expectations on which there is some consensus. It stabilises an otherwise uncertain world of knowledge. In other words, intellectual property tells you a story. But one cannot tell a story without first knowing where one stands. And for that I need another story.

Let me tell you a story of Hermes and the catalogue of intelligence and story over which he prevailed. I do this because intellectual property is an almost magical, hermetic narrative. In ancient Greek mythology, Hermes was of course the great messenger and patron of boundaries, the patron of commerce.

After Zeus had fashioned the human race, he ordered Hermes to give them intelligence. Hermes divided intelligence into equal portions and then applied it to each person. (Aesop,

Fable 320)

He allotted each individual their share of intelligence, their distinctiveness. Like Hermes, the intellectual property system also preoccupies itself with the limits and objects of our cultural catalogue. It provides for us the tools and language with which to decipher within the field of knowledge those discrete objects of intellectual endeavour, and to exchange and promote and reproduce them. And like Hermes, also known as the god of searches, intellectual property too is a search for authenticity - the sufficiently distinctive, the sufficiently new, the sufficiently inventive.

Like Hermes, the patron of storytelling, literature and invention, intellectual property tells us a story of our cultural progress, marking the milestones or episodes in that progress by which we recognise the narrative itself. Hermes' great task was to create the conditions for story, the signposts for narrative, the Hermae (or large stone pillars), assisting the narrative travellers along their paths. When passing a point, a stone would be laid by each passenger, accumulating tributes to the god - a Hermean heap - as well as improving the roads along the way, thus facilitating commerce. Such pillars are thus also tributes to what has gone before, an artefact of the journey, just as the objects of intellectual property are also artefacts and landmarks in the narrative of cultural invention. Just like marks on the trade mark register, the library of patents, a database of designs, all these signposts assist with driving the narrative and clearing the path.

The storyteller is in stark contrast to the hundred-eyed Argus Panoptes.

Hermes was commanded by Zeus to release Io, a favourite of Zeus, from the surveillance of Argus, appointed to guard her by Hera. In so doing, Hermes was to achieve this task without force. However, even in his deepest sleep, Argus with the 100

10. Serres M, The Five Senses: A Philosophy of Mingled Bodies (I), M Sankey \& P Cowley (trans), London, Continuum, 2008 [1985], page 40. 
eyes was every watchful and could not be surprised. Hermes' strategy therefore was to use noise to triumph over vigilance. He thus invented the pipes and played such charming music to Argus and told him such stories that he bewitched him with the confidence to sleep. Argus - at once all-seeing and all blind - was defeated.

Argus was then slain by Hermes and his eyes immortalised in the tail of the peacock, the ultimate display of vanity, of celebrity - eyes that do not see. Hermes thus outwitted sight with sound. Sound is everywhere, sight is situated. Hermes is the network, the narrative, Argus is the singular event.

There is much to enlighten in this story, this story of storytelling. The system of intellectual property cannot possibly account for every perspective at every moment in order to provide a perfect replication of the world's cultural knowledge. And yet it remains seemingly the most 'complete' system that is understood and accepted. How that impression is created is precisely due to the compelling narrative told by intellectual property, the noise in the system as distinct from the local and limited objectivity of Argus. Confidence in the system is engendered by confidence in the story, in the precedent, in the landmarks - the story of intellectual property.

In a way, people are hungering and thirsting for epic. I feel that epic is one of the things that men need. ${ }^{11}$

And that story is an epic tale: a tale of accomplishment and decline, of rhythm and cadence. So this is what I'm faced with, this incredible journey, this epic tale. The story is undeniably grand. In its entirety, the intellectual property system appears to gather together the intellectual output of a globalised world and identifies it for us so that it might be recognised, rewarded, valued and exchanged. In this way, by its very recognition within the intellectual property framework, a product is legitimated as creative, original, distinctive, new, and innovative. This sounds like myth-making, but the crucial difference is that intellectual property is not interpreted so much on history as it is on futures. It is true that in a common law jurisdiction, we consolidate the story through decisions in the courts. But intellectual property development is always necessarily looking forward and always presenting itself, rightly or wrongly (for this is the mechanism for a grand narrative), as international.

... the important thing about the epic is a hero. ${ }^{12}$

Of course, the central articulation for any epic is the hero. But who are the central protagonists of intellectual property?

First, as all good students of literature will know, to identify someone or something as the hero is not to make any judgement of value in that individual. Indeed, heroes can be flawed, naïve, unreliable, like Macbeth for instance. So my daily work, my research, involves getting to know these characters, in all their detail.

The important thing about character is that within any particular character in any story there is the attempt to abstract the world of the story in that individual. The character both summarises and multiplies the story. And intellectual property rules achieve something very similar in a brilliant and sophisticated way. Within the intellectual property system, we have a legal representation for the entirety of literary, artistic, musical and dramatic works (through copyright); for the inventive and industrious

11. Borges JL, 'The Telling of the Tale', This Craft of Verse: The Charles Eliot Norton Lectures 1967-1968, C-A Mihăilešču (ed), Cambridge MA, Harvard UP, 2000, page 53.

12. Borges JL, 'The Telling of the Tale', This Craft of Verse: The Charles Eliot Norton Lectures 1967-1968, C-A Mihăilešču (ed), Cambridge MA, Harvard UP, 2000, pages 48-49. 
outputs of our society (through patents); for the ingenious and distinctive ways in which we identify our commercial enterprises (through trade marks); for the beautiful in what are otherwise functional objects (through design). Intellectual property characters, therefore, comprise all the parts therein. At least, so it seems.

These are the main characters, if you like, the heroes. Notably, however, in all good narrative, characters are likely to change, to develop, to restore. But characters are also necessarily part of the narrative, contained and existing within the literary sequence in which they travel, in which they are plotted. In the intellectual property epic, these heroes are necessarily part of the narrative journey itself. It is the literary system that is of particular importance.

And what are the minor characters in this story, those characters that are essential to the story but nevertheless peripheral to the heroes? The 'side-kicks' if you like. Minor characters may simply be part of the context, or they may shed an important perspective on the main story, or even provide the necessary turning points, changing the action altogether.

The minor characters in this story include appellations of origin (for agricultural products and wine) - not so minor when you consider their appearance in the Treaty of Versailles. ${ }^{13}$ Other minor characters include the protection for plant varieties, database rights (protecting the labour and investment in creating a database), semiconductor topography rights (protection for the layout of semiconductor chips), and artists' resale royalty rights (or droit de suite) entitling artists to a percentage of the resale of any original artwork. ${ }^{14}$ The latter is of particular intrigue in this narrative, in that it is one of the only places where the law deals with the original and unique object, as distinct from the abstracted form in its potentially infinite reproduction. The otherwise globalised noise of intellectual property is silenced in the original, localised perspective of the work of art.

The anti-hero is perhaps less fortunate than the traditional heroes of intellectual property. The anti-heroes perhaps do not enjoy the same calibre of esteem, respect and grandeur as the heroes (and indeed, may even be rejected outright as completely contrary to the narrative). They simply lack the same heroic and grand characteristics (at least from the perspective of the story to be told) that ensure the prominence of the hero. Nevertheless they are central to the story, and they are central to the modern epic of intellectual property, as I hope to show later in this lecture. The one thing that all these anti-heroes have in common is that their subject matter is relationships between people as distinct from relatedness to objects. The perspective of these anti-heroes is startling in its contrast to the cacophony of our heroes. So allow me to introduce some of the anti-heroes in this story.

Traditional and indigenous knowledge refers to the collective yet differentiated knowledge of traditional and local communities, including the entire array of cultural expressions, dance, painting, costume and dress, story, spirituality, medicinal and agricultural knowledge, biodiversity and environmental knowledge, secret and sacred knowledge; that is, all knowledge that is constitutive of that traditional community's cultural identity and values. Traditional knowledge is also holistic, challenging the conventional categories represented by our heroes. For instance, the didgeridoo is an instrument of Australian Indigenous peoples documented to around 1500 years ago

13. Article 275.

14. Artist's Resale Right Regulations 2006 (SI 2006/346); these Regulations implement Directive 2001/84/EC of the European Parliament and of the Council of 27 September 2001 on the resale right for the benefit of the author of an original work of art. 
but in all likelihood much older than that. The word itself is an invention of the colonisers - derived from the sound made by the instrument itself. Importantly, the construction of the didgeridoo is achieved not primarily by people but by the forest itself. It comes from only certain particular species of Eucalyptus tree, the branches of which have fallen to the ground or have been harvested. The branch is then left to be hollowed by termites, producing irregularities that contribute to the distinctive and unique sound, as well as the particular qualities with respect to the Dreaming. The instrument is thus made from the forest and its playing is a tribute to the forest, a narration of the land, thus fulfilling responsibility to tell that story on the part of the Indigenous peoples. Traditionally played only by men, the process of the didgeridoo incorporates a range of knowledge and skills - technical and environmental knowledge, technology in the paint itself, ceremonial adornment and painting, ceremonial dress and dance, storytelling, music and art. This process defeats the attempt to identify episodes in the knowledge, or categories of knowledge according to the conventional objects of intellectual property. Such knowledge is also marginalised by the intellectual property system in that much of it comprises ancient knowledge, collective or communal knowledge, without identified authors or inventors, and without documentation. Tradition as a mechanism of knowledge generation suggests also incremental and evolutionary forms of innovation, as distinct from the 'inventive' events recognised by intellectual property. And yet the result is remarkable and resilient.

Trade secrets and confidential information constitute anti-heroes in that this is entirely counter to the dashing brilliance and publicity of the conventional intellectual property rights. Closeted and secret, trade secrets are uncertain, unreliable, untested anti-heroes.

Similarly, privacy is concerned with communication, but in terms of its restriction. Precisely the activity of publishing that is so central to the fundamental principles of intellectual property protection, is the very same activity that is challenged by privacy.

And finally, human rights. Again, to identify something as an anti-hero is not to make a value judgement, but to articulate the position within the story. So what is the uneasy position of human rights in relation to the commercial and economic emphases of intellectual property protection when we consider the protection of pharmaceuticals with patents, the protection of educational texts by copyright? Current issues like the prices of pharmaceuticals and access to medicines, not only in developing countries but also for our own National Health Service (NHS), or access to resources for education and libraries, all test the limits of the social contract between users - that is, between consumers and the owners of intellectual property and their opportunity to define the market in which the consumers seek access.

The anti-heroes are concerned primarily with relationships, not with objects. They are concerned with questions of identity and dignity, through relationships between people but not between objects. The narratives are seemingly untranslatable within the dominant discourse of the intellectual property framework. The resolution to these issues therefore will necessarily come in the resolution between these inconsistent stories.

This distinction between relationships and object relations is taken to an extreme in the qualities of surveillance and stealth that characterise the villains in this piece censorship and celebrity. These two villains are characterised by a deprivation of objects. Censorship chooses to veil the object in secrecy. Celebrity is deprived of objects altogether, producing nothing and relying on a mythology attached to a jealous panoptic vigilance cataloguing in forensic detail the mediocrity of everyday life. 
In the absence of objects, in the absence of hermetic noise, we have a preponderance of panoptic obsession, the peacock's tail. Celebrity is all-seeing and at once blind, producing nothing. The surveillance that characterises celebrity is the spectre of something creative. But this does not amount to observation that might be seen as characteristic of the creative and innovative industries. It is merely shadows. What we have in celebrity is not so much a detective story as a novel of sensation.

More disconcerting than the villains are the false friends, the wolves in sheep's clothing. In today's story, these might surprise you. So who are the three gargoyles in this story?

For the uninitiated, Creative Commons and Free and Open Source licences are devised in order to make accessible copyright works for use and re-use. In certain instances, Creative Commons and Open Source licences may allow further commercialisation of any adaptations or incorporations of the work. Free Software licences, on the contrary, prohibit any subsequent privatisation of the code.

Both Creative Commons and Free and Open Source models have in the past evangelised their positions as alternatives to intellectual property in order to disseminate the materials without restriction. But they are not alternatives; they are in fact completely reliant upon intellectual property. In order to enforce such conditions in a licence, there must be subject matter on which to do so. This is the very subject matter of copyright.

These are wolves in sheep's clothing - at least, they do not necessarily do what it says on the outfit.

A foil is that character that emphasises the character of the hero, the protagonist, by its direct contrast with the hero. The distinctive qualities of intellectual property are emphasised by none other than competition law. Whereas intellectual property rules allow owners of intellectual property to enjoy exclusive rights for a period of time, thus making it possible to manipulate the market for an otherwise inexhaustible good, competition law seeks to restore the balance, challenge the heroes' privileged position and disarm them.

Finally, what might be the arch nemesis of our heroes in this epic tale? What may overtake and befall the tragic heroes? In the classical sense, the nemesis is a kind of punishment for the audacity and presumptuousness of the heroes. Perhaps nowhere has this audacity been more clearly ill-founded than in the digital world. And so the arch nemesis of our heroes is none other than ...

... Google.

So, now that we have met the cast, what is the story so far?

Primarily, the rationale for intellectual property protection is to ensure the dissemination and exchange of knowledge and cultural output, by creating an environment in which the producers of that output can feel confident in their identity (they are recognised, attributed and so on) and that they can reap the benefits of their skill and efforts without someone else taking all the credit and glory.

Therefore, intellectual property is preoccupied with access to those materials and about preserving the identity of those materials. This suggests maintaining the integrity of identity not only from the point of view of accurate attribution and credit, but also in terms of cultural appropriation and misappropriation.

The key articulating value here is that of use - the ability to use the materials, the extent to which one can use the materials, and the kind of use to which those materials can be directed. Such use ranges from conventional forms of consumption to ownership itself. The character of 'use' is thus the intrinsic value of intellectual property, it is the way in which participants in the system derive meaning. And in so doing, 
that use is not wasteful (does not destroy the identity of the author, the authenticity of the product). Use can also be regenerative - it is precisely this quality within the system that ensures the followers, the new creators. The ideas themselves cannot be exhausted, but access to the abstracted forms of those ideas, the objects of intellectual property, can be limited. It is where that access interferes with use - to the extent that it interferes with the narrative of new innovation and creativity - that the literary schema begins to crumble. In other words, use is the very opportunity of intellectual property which, if obstructed, defies the utility of the system.

Furthermore, in making use of intellectual property, the audience, the user, the consumer is not merely a passive recipient. Each of us consumes new products of cultural life with a degree of intrigue and strategy, with an element of personal satisfaction. We use those products not only for information and knowledge, but also for a sense of identity, a sense of self. Our cultural life also positions each of us within the larger literary schema of things. It is in the use made of the product that these various narratives interconnect and resolve. It is exactly these possibilities that make the cultural products useful.

With it, the key principle of consumption, of use, ushers in two key issues - that of quality (in an age of mass production and increased commodification of the object, the original knowledge is displaced by the infinite replication of its abstracted form); and fairness (not only in terms of the distribution of the products and the access to those products, but also in terms of the circumstances for the labour invested in those products and the conditions for their production. What does, or can, the intellectual property system say about the quality of the objects that comprise our cultural catalogue? Or indeed the broader ethical context in which those objects are produced and distributed? In other words, what does the intellectual property system say about value and fairness?

The inventive event is the quotation and the narrative. ${ }^{15}$

Speech, narration, this inaugural itself is also premised on use - I am using, paying tribute to, my subject matter and indeed the people acknowledged. In other words, scholarship is always a type of speech, a story, articulating the various contributions to the field and resolving them at any one moment towards beginning the next inquiry. Intellectual property is similarly a framework built upon citation. Where necessary, tributes are explicitly quoted and identified, departures and differences therefore possible, remarkable, and rewarded. The entire field of intellectual property is a story and system of quotation. Sometimes of course the boundaries are unclear and following appears more like imitation. It is these points in which confusion may occur and the narration becomes unreliable. Such unreliable narration is necessarily arbitrated by the ultimate narrative device, the judge. In a literary sense, does this suggest that the judge is in fact the author of the intellectual property narrative, the ultimate voice? Or is the judge simply a literary device, a minor character?

Whatever one's perspective, telling the story of intellectual property is essential to its scholarship and development. Indeed, the greater the discussion and exchange, the richer the narrative that takes hold. It is in the modern academic context in which we are seeing genuine exchange between lawyers, policymakers, users, civil society, industry, students and academics, that authentic innovation in the network is possible. Indeed, there is a clear and present danger in silence.

15. Derrida J, Acts of Literature, D Attridge (ed), New York, Routledge, 1992, page 324. 
There will be no telling of stories, adventures or other such talk that distracts the workers from their work. ${ }^{16}$

Silence in the past has been a rigorous and oppressive management tool - the industrial revolution revered silence as a form of control. ${ }^{17}$ I cannot help but think the open office is a subtle and sophisticated version of this Fordist model of industry, where openness actually limits conversation - how can one speak when one is under constant surveillance? Has Argus reasserted surveillance over the noise of Hermes? In these models, speech is denigrated as gossip, however contemporary management models note the barrier silence poses to innovation and creativity ${ }^{18}$ and thus, it may be extrapolated, also adaptability.

To rob a man of his language in the very name of language: this is the first step in all legal murders. ${ }^{19}$

Speech is constitutive not only of community but also of the individual. As for other intersecting narratives, this is a critical way in which the individual can measure behaviour against wider expectations. Therefore speech not only tests social norms but also re-instates them. This narration of one's own identity and one's community is not only a measure of speech but also a mechanism of the entire catalogue recorded by the intellectual property system. Both the objects themselves and the decisions that resolve the various narratives in litigation engender confidence not only in the system but also in our cultural life more broadly speaking. The intellectual property system tells a story and in so doing creates resolution and stability.

Storytelling also provokes an obvious question - who speaks? In other words, what is the subject of intellectual property capable of identifying itself as the 'author'? In this very action of the inaugural, it is speech and the act of speech that qualifies the 'who', that identifies the professor that I am here to proclaim I have become. In other words, storytelling and speech is what constitutes identity. This is the brand, established by story. Such branding or naming, if you like, is based upon the notion of attribution, of respect and esteem. Story attributes an action to the speaker, to the narrator. Similarly, the law attributes an action to its subjects. Intellectual property attributes the author, the creator, the inventor. Indeed, the very process of transferring intellectual property is called assignment - that is, assigning that action to another, notwithstanding that this other is not the original source of the action. That assignee becomes the who, the agent, identified by its relationship to the intellectual property. Such identity is central to the process of assigning rights and duties that correspond to that relationship. Indeed, this is the narrative structure of legal frameworks and the judicial process, where the courts rely on reconstructing histories to establish responsibility on the part of the individual characters. Story is therefore the process by which identity is established and stabilised. Intellectual property does not protect mere information (the genetic code for instance), it protects story (what does that code do?). Intellectual property is, like Hermes, at once the messenger and the message.

16. Amboise cited in Foucault M, Discipline and Punish: The Birth of the Prison, A Sheridan (trans), London, Penguin, 1977 [1975], page 151.

17. Salmon C, Storytelling: Bewitching the Modern Mind, D Macey (trans), London, Verso, 2010 [2007], page 36.

18. Salmon C, Storytelling: Bewitching the Modern Mind, D Macey (trans), London, Verso, 2010 [2007], page 37.

19. Barthes R, 'Dominici, or the Triumph of Literature', Mythologies, A Lavers (trans), New York, Noonday, 1990 [1957], page 46. 
The message of intellectual property, in other words, becomes the object itself. The patent supplants the invention, copyright overcomes the book, design multiplies the handbag, trade marks immortalise the name. The narrative of intellectual property becomes the cultural artefact, not the objects. It seems no longer possible to subsist outside the narrative of intellectual property. The data on the intellectual have seemingly been substituted for the world and what was once an objective world of objects, has now overcome itself as a world of relationships again, of narrative, of myth. Hermes, the messenger, becomes the message. The objects of intellectual property are mere abstractions, mere characters. The intellectual property narrative has substituted itself for culture.

For taste must be an original faculty; whereas one who imitates a model, while showing skill commensurate with his success, only displays taste as himself a critic of this model. ${ }^{20}$

The exemplary nature of each recorded event in intellectual property thus facilitates the narrative, promotes following, but not imitation - taste is an original faculty and a faculty of originality. This is often confused as the distinction between innovation and tradition. However, tradition is but a mechanism, a story for innovation. The way in which that story is told, however, is perhaps entirely different. Traditional and indigenous knowledge, therefore, does not translate easily into the narrative of intellectual property, which, through its universality, thus reflects such knowledge as suspicious, outside the fundamental concepts so dear to intellectual property frameworks. The collective, authorless, disordered, unoriginal, unchanging, retrospective folk tale of traditional knowledge is thus a foil to the magnificent universality of the prospective epic of intellectual property. According to the story of intellectual property, the former surely catalogues knowledge, but the latter creates objects, creates the new. The former observes knowledge in the world, the latter acts to produce it.

Remember also that technology always means new technology. ${ }^{21}$

This quest for newness is so central to the intellectual property narrative that it belies its preoccupation with history and change. History, however, is edited and selected, yet it suggests the complete picture. It is presented as thorough, comprehensive and memorable. Similarly, the story of intellectual property is the very mechanism by which is communicated a sense of completeness and universality with respect to the way we judge innovation, invention, originality and value, even though we know that much is unimaginable and inconceivable within that history, such as traditional and indigenous knowledge.

The taste is a commyn witte, Spraden throgh the body, but hit Shewyth hym most by the handys (1422 tr. Secreta Secret., Priv. Priv)

Indirectly, thus intellectual property is implicated in the constitution of universal taste. Taste is of great interest and significance in the context of intellectual property, in that taste immediately implicates the consumer, the user. Indeed, the concepts of consumer and taste have developed together. ${ }^{22}$ The word 'taste' in fact originally referred to the sense of touch or feeling making taste literally, therefore, the common sense.

20. Kant I, The Critique of Judgement, JC Meredith (trans), Oxford, Clarendon P, 1952 [1790], Book I: Analytic of the Beautiful.

21. Lyotard J-F, Peregrinations: Law, Form, Event, Columbia UP, 1988, page 28.

22. Williams R, Keywords: A Vocabulary of Culture and Society, London, Fontana, 1976, pages 314-15. 
Taste, like judgement in general ... gives stability to the ideas, and qualifies them at once for permanent and universal approval, for being followed by others, and for a continually progressive culture. ${ }^{23}$

Taste, that is touch, fixes sensation. Intellectual property similarly closes a moment in intellectual progress - the expression binds the copyright text, the patent defines the invention. However, what of the arch nemesis in this story? In a digital world, where is the outline of the object? Where is the outline in a world where there is nothing but text, nothing but fragments?

History is merely gossip. ${ }^{24}$

The outline, perhaps, comes from storytelling itself. Gossip is inextricably history. Clearly the narrative, the storytelling is thus not idle gossip. It is a form of action, of creativity and thus of productivity - a form of creativity that re-stabilises the epic of intellectual property itself. One must look to the creativity and adaptability of the system itself in order to face new perils along the journey. That adaptability comes from the narrative itself.

Indeed, new business models themselves attempt to confront the arch nemesis of Google by relying heavily on the creativity of story - for instance, the reinforcement of fan-based cultures, links to the artist, and the derivation of value from the approbation of followers as distinct from ring-fenced value in the objects to be merchandised. In a way, new business models are moving from sight to sound, to story, just as Dickens did in 1867.

These are the fragments, the interruptions, the minor narratives that interfere with the seamlessness of the dominant narrative of intellectual property. In telling stories, there is a challenge to Hermes himself.

Stories communicate names, branding and characterise the field. In a way, does this not implicate the notion of idle gossip, of celebrity? One only has to read of the many examples of inappropriate disclosures by individuals in positions of responsibility, accountability or mere fame to see the perils of storytelling. What is presumed in the infinite scrutiny of celebrity, of Twitter, of Facebook, is an ironic intimacy. But for what we are nostalgic is gesture, touch, indeed taste. In the transformation of communication to the screen, something is lost such that the reality of surveillance is obscured. The reality that is presented denies its shadow. In presenting everything we are presented with nothing. And as we all know, Google never forgets.

But there is something about a tale, a story, that will be always going on ... I think the epic will come back to us. ${ }^{25}$

What we are facing now is a kind of crisis point in our heroes' destinies, a digital postmodern condition for intellectual property, if you like. The story itself becomes a basis for action and the very solution for the adaptability to be found within the system itself. The attempt to universalise cultural output within the intellectual property framework in itself has generated the challenges before it and is the source of instability inherent in the law. From the expansion of subject matter coming within protec-

23. Kant I, The Critique of Judgement, JC Meredith (trans), Oxford, Clarendon P, 1952 [1790], Book I: Analytic of the Beautiful.

24. Wilde O, Lady Windermere's Fan: A Play About a Good Woman, 1892.

25. Borges JL, 'The Telling of the Tale', This Craft of Verse: The Charles Eliot Norton Lectures 1967-1968, C-A Mihăilešču (ed), Cambridge MA, Harvard UP, 2000, page 55. 
tion, or the challenges presented from the expansion of opportunities and horizons presented by new technologies, these challenges are epic.

Once a world of objects outlined by the narrative of intellectual property, how does our world now look in a digital environment? How does the practice of outlining and demarcating objects of intellectual property persevere in a digital world, a world with no outlines, no territories - a world of nothing but text? Is the digital world really the arch nemesis or the very opportunity for the heroes to prevail and be restored?

If I am not mistaken, the heterogeneous pieces I have enumerated resemble Kafka; if I am not mistaken, not all of them resemble each other. ... In each of these texts we find Kafka's idiosyncrasy to a greater or lesser degree, but if Kafka had never written a line, we would not perceive this quality; in other words, it would not exist. ${ }^{26}$

This brings me back to the question of identity. In this digital world of self-promotion and infinite connection, how does one protect the limits of one's identity, reputation, privacy? How does one define the creator? Knowledge objects are themselves chimera - an infinite hybridisation of what has gone before.

Intellectual property both acknowledges and denies this, denigrates and reveres this. In a very literal sense, plant and animal varieties are manifestations of this attention to the synthesised fragments of knowledge. This brings us back to the important and indeed essential question of use. The principle of identity, therefore, is not necessarily in the object itself, but in its naming - that is, in its use, not its creation. It is in the perspective of the user, that the object realises its potential. It is in use that the object is characterised. This is entirely familiar to intellectual property law. There is nothing inventive about pure information; and what is a genetic sequence, but the mere information encoded in our bodies? What is of interest is what that information can do, that is, when assembled, the story that it tells. When it comes to gene-related inventions, the law has resolved this dilemma, by tying the inventiveness to the use, or purpose-bound protection as it is known.

Indeed, it is in use that we capture the very ethics of intellectual property. The ability to use the material is precisely the ethical result of the frameworks in place. Any respect for the law, any legitimacy that it continues to enjoy within society, must come from this ethical perspective on intellectual property, this consideration of its use.

The narratives of the world are numberless ... narrative is international, transhistorical, transcultural: it is simply there, like life itself. ${ }^{27}$

It is therefore of considerable importance to the greater narrative of intellectual property, that these individual stories, these fragments, these crises, are preserved and recounted towards the resolution. Diversity is a quality in and of itself, and indeed its preservation is crucial to scientific and cultural progress, to adaptability and to advancement. In our cultural and intellectual catalogue, the repositories for such diversity include biological and genetic resources, cultural resources and heritage, and indeed the processes of knowledge generation themselves.

It is important therefore to resist the construction of a monoculture for knowledge production, as a matter of inevitability, when we construct the meta-narrative

26. Borges JL, 'Kafka and his Precursors', Labyrinths: Selected Stories and Other Writings, JE Irby (trans), DA Yates \& JE Irby (eds), New York, New Directions Books, 1964, page 201. 27. Barthes R, 'Introduction to the Structural Analysis of Narratives', Image Music Text, S Heath (trans), London, Fontana, 1977, page 79. 
of intellectual property. Further, it is of considerable enlightenment to consider the intersection of the intellectual property narrative with these other fragments. What might the narrative of intellectual property, in all its epic magnificence and adaptability, have to say about the circumstances for preserving the important fragments within our cultural life? How might the intellectual property system promote not only innovation and creativity in the objects themselves, but also in the conditions for their production? This latter part of the story is equally fundamental to the narrative of innovation and creativity. Diversity is in and of itself a value for innovation. So, let me tell you another story, a parable if you like, to explore such opportunities - a 'shaggy dog tale'.

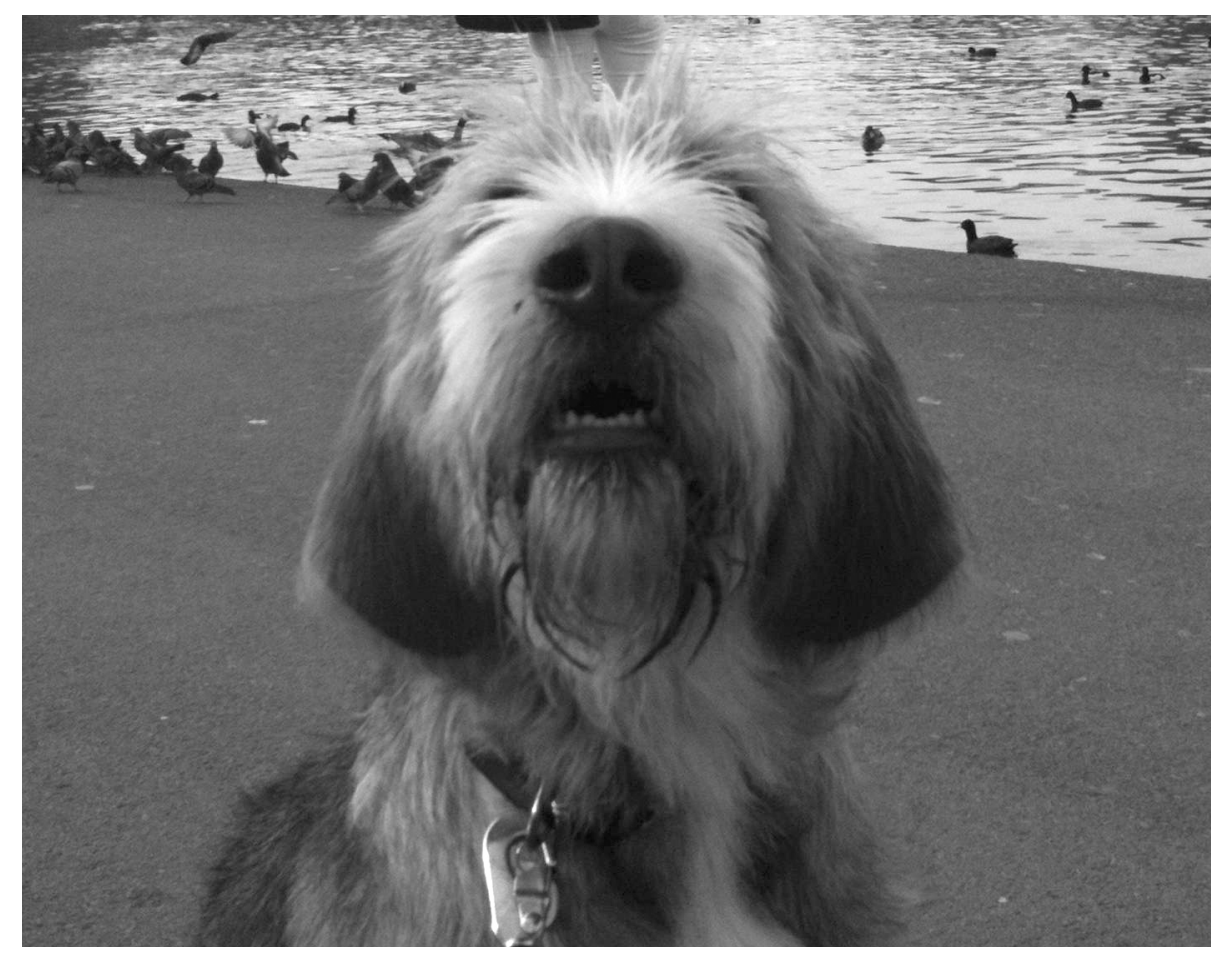

This is Finnegan - one of the characters in my own life and a useful test for the way in which intellectual property might come to bear in some rather unexpected ways. It is perhaps more than a mere shaggy dog tale. It is more adequately described as literary fable, particularly when the protagonist is a dog, as is convention. This is a fable of the intersecting narratives that provoke development in intellectual property. Cultural life cannot be presented merely by the representations offered by our heroes. For the narrative to be complete, an appreciation of the various fragments is necessary.

Finnegan is an endangered breed, the Otterhound. There are now fewer than 800 Otterhounds left worldwide. Finnegan was one of 57 puppies born in the UK in 2009, as compared to the Labrador Retriever, where 40,943 puppies were born in 2009 going up to 44,099 in $2010 .{ }^{28}$ This makes the Otterhound one of the most endangered dog breeds in the UK and indeed the world.

28. Statistics provided by the Kennel Club. 
Commission for John Parry, Master of the Otter Hounds, to take up dogs for the King's diversion; all millers commanded to stay their watercourses, at the time of hunting the otter (10 November 1604).

'James I: Volume 10: November-December, 1604', Calendar of State Papers Domestic: James I, 1603-1610 (1857)

The Otterhound is also one of the most ancient and allegedly royal of the British breeds, recognised throughout oral, artistic and literary traditions in British culture. It is thus part of British cultural heritage and agricultural history. There are references to 'Otter dogges' in the literature that date back to the 12th Century. It is reported that King John (1199-1216), of Magna Carta fame, kept one of the earliest packs of Otterhounds.

The recognition of the breed itself also dates back to the establishment of breed registers in the UK. It was one of the first breeds recognised by the Kennel Club, being recognised in 1874 shortly after the establishment of the Kennel Club itself, 4 April 1873. ${ }^{29}$ The breed was recognised by the American Kennel Club in $1909,{ }^{30}$ where there is also a systematic programme towards the conservation of the breed.

The Otterhound peaked in popularity in the Victorian period. In the mid 19th century the Squire James Lomax of Clayton Hall, Clitheroe was known for having one of the most famous and superior packs, having trained them to react to the most subtle of hand signals and commands.

At this stage in the Otterhound's history, it was the skill and training that was of primary importance, rather than the hunt itself. Unfortunately, following a rabies outbreak, it is said that all but three were destroyed and James Lomax never developed a new pack. The legend is that he never wanted to suffer from comparisons with his earlier hounds, and could not bear to build a new pack as a result.

This training and discipline is maintained to this day, with particular insight and knowledge transmitted through generations that keep and work modern packs, although no longer for hunting. The Otterhound has enjoyed some contribution to tracking and search procedures for instance, as well as some potential as medical alert dogs and accreditation also as therapy dogs. This history of aptitude, discipline and training is integral to the heritage embraced in the modern Otterhound (if, however, not quite embraced in Finnegan).

The conservation of rare and endangered agricultural and domestic breeds is a priority for conserving genetic and biological diversity as well as the historical and biological significance of genetic purity within any one breed or variety.

The Otterhound is a prime example of cultural heritage and future potential, in that it embraces hundreds of years of British cultural and social history, as well as enormous potential in the medical and rescue fields alone due to their remarkable capacity as scent hounds. The European Livestock Breeds Ark and Network (ELBARN), ${ }^{31}$ now continuing as the Safeguard for Agricultural Varieties in Europe (SAVE) Foundation, ${ }^{32}$ and Rare Breeds International $(\mathrm{RBI})^{33}$ identify in their work

\section{The Kennel Club. \\ 30. Information provided by the American Kennel Club. Foundation. \\ 32. <http://www.save-foundation.net> \\ 33. <http://www.rarebreedsinternational.org >}

31. The European Livestock Breeds Ark and Rescue Net began in 2007 with a three year project funded by the European Commission under the work programme of Council Regulation (EC) No 870/2004. This project was completed with the publication of the final report in 2010. The European network for livestock breeds will be continued into the future by the SAVE 


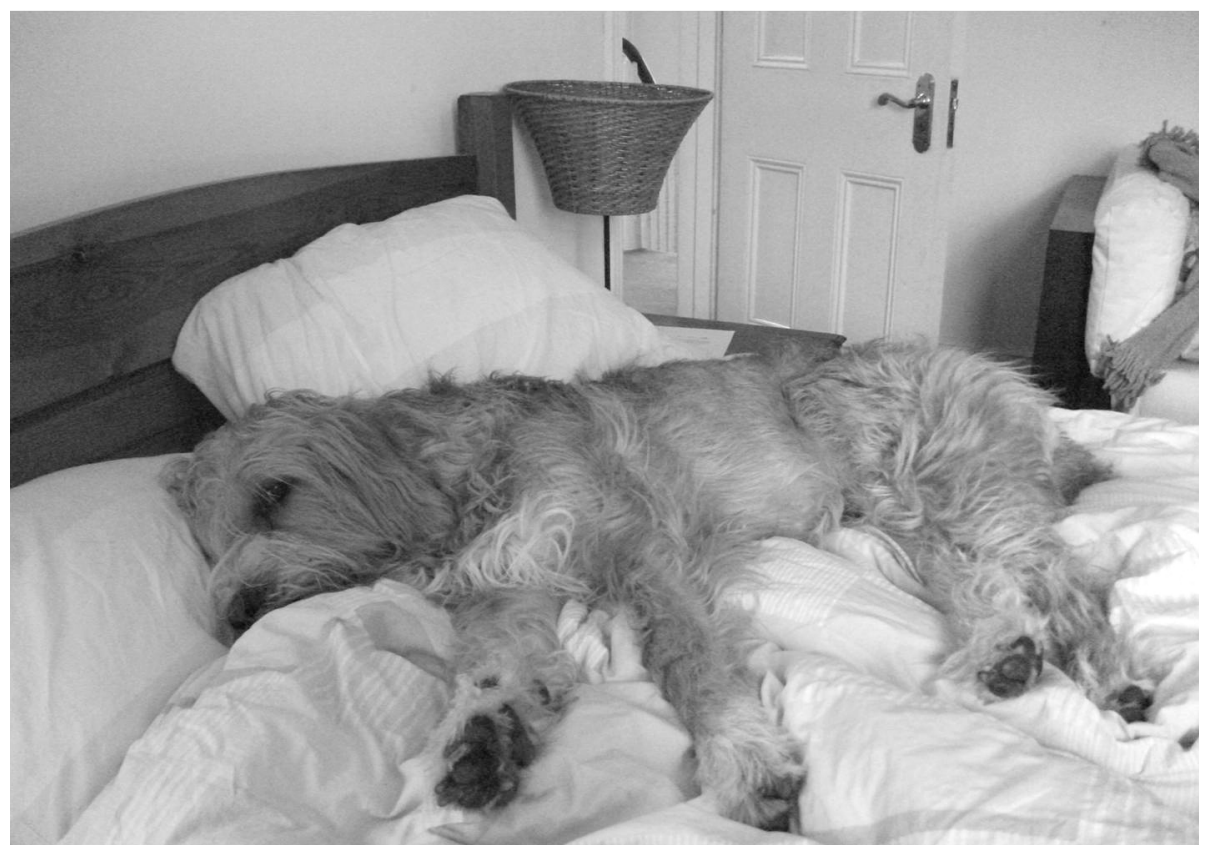

programmes domestic companion animals, including dogs, as priorities for preservation.

By telling Finnegan's story, several issues are raised - first that of the audience (is there an audience for the Otterhound?) and that of use (for example, how might the cultural heritage inhering in the Otterhound play out in modern times, in the absence of hunting?). Story engenders interest and proximity, creates value, the kind of fanbased remedy deployed by Dickens and interrupting this lecture throughout. How Finnegan's story reconciles if at all with intellectual property is an intriguing puzzle, but one which I hope serves to illustrate, in microcosm, the character of this entire discussion this evening.

'Change' is scientific, 'progress' is ethical; change is indubitable, whereas progress is a matter of controversy. ${ }^{34}$

How might it be possible to reconcile the issue or preservation, of conservation, with the system of intellectual property? The first question of safeguarding the object is contrary to the principles of the intellectual property system, which safeguards change - that is, the system charts cultural expression in order to facilitate change, the new, the continuing progress of the narrative, to clear the path for commerce. The adaptability and future of the intellectual property system, however, relies on the quality of its encounters with contrary narratives, including the ones posed by traditional knowledge, intangible cultural heritage and genetic resources. How it manages those narratives and incorporates those streams will serve to strengthen and expand the breadth of this epic tale.

34. Russell B, 'Philosophy and Politics', Unpopular Essays, Oxford, Routledge, 1995 [1950], page 19. 
For Finnegan then, the future is in tradition - that is, in British traditional knowledge and the many intersecting narratives therein. But the example raises specific issues about traditional knowledge in the British context: namely, the importance of promotion in this example (that is, dissemination) as distinct from any perceived limits to access; the importance of the consistent integrity of the breed itself (as a repository of genetic diversity); and the transformation of traditional knowledge in a contemporary context where the original use (in this case hunting) is no longer relevant, but the historical knowledge and skill may be reapplied in new and vital ways. In other words, tradition is a mechanism by which skills are transmitted and new knowledge developed, while at the same time the integrity and sustainability of a particular breed (and its genetic diversity) is protected. The example shows us that traditional knowledge is not ossified and static, but is resilient and relevant.

This is not strictly an intellectual property issue, and yet the values at stake share much with the rationale of the intellectual property system - dissemination and use, quality and identity. Intellectual property may assist in obvious ways - registration of the Kennel Club's marks (the Kennel Club mark itself and the Accredited Breeder Scheme mark, for example, which stand for quality and fairness, including the welfare of the dogs) - but its application or adaptation to the specific issues of traditional knowledge would be contrived at best and disastrous at worst. It is a system to be applied alongside any proposals for protection of traditional knowledge, but is not the resolution in and of itself. What is informative about this story is the intersection between intellectual property and traditional knowledge. The UK has ratified the UNESCO Convention on the Protection and Promotion of the Diversity of Cultural Expressions, ${ }^{35}$ which is guided by, amongst other things, the principles of sustainable development and equitable access. One of the important objectives of the Convention is 'to give recognition to the distinctive nature of cultural activities, goods and services as vehicles of identity, values and meaning., 36 This is a vehicle of promotion and dissemination as a mechanism for protection, that is, for ensuring sustainability and preservation through use.

Once again, the ethics of the system rest in use - use which is relevant, meaningful and assured.

But there is something about a tale, a story, that will be always going on. I do not believe men will ever tire of telling or hearing stories. ${ }^{37}$

And so I end where I began, a beginning, a commencement, one to which I am committed sincerely and bound historically. Thank you for being here at this point in my career, and in letting me share with you the story of intellectual property, and the story of what I do. Indeed, this is why I love what I do, the opportunity to read and hear so very many stories.

\footnotetext{
35. 2005 .

36. Article 1(g). 'Cultural activities, goods and services' are defined in Article 4.4 as referring "to those activities, goods and services, which at the time they are considered as a special attribute, use or purpose, embody or convey cultural expressions, irrespective of the commercial value they may have. Cultural activities may be an end in themselves, or they may contribute to the production of cultural goods and services."

37. Borges JL, 'The Telling of the Tale', This Craft of Verse: The Charles Eliot Norton Lectures 1967-1968, C-A Mihăilešču (ed), Cambridge MA, Harvard UP, 2000, page 55.
} 